\title{
Un servidor de la renovación litúrgica en España: Manuel Garrido Bonaño (1925-2013)
}

A Servant-man of the Liturgical Renewal in Spain: Manuel Garrido Bonaño (1925-2013)

\section{Alfonso BERLANGA}

Universidad de Navarra, Facultad de Teología

https://orcid.org/0000-0001-8503-3968

aberlanga@unav.es

Abstract: The life and work of Manuel Garrido Bonaño, OSB (1925-2013), are essential to understand the evolving liturgy of the 2oth-century. His liturgical formation, his participation in the Second Vatican Council, and his role in the liturgical renewal have made him an important witness. The picture of his life provides first-hand accounts on the evolution and aims of the Liturgical Movement in Spain.

Keywords: Garrido Bonaño, Liturgical Movement, Second Vatican Council, Benedictine Order, Liturgy.
Resumen: La vida y la obra de Manuel Garrido Bonaño, OSB (1925-2013) constituyen una fuente importante para comprender el devenir de la liturgia en el siglo XX. La formación litúrgica que recibió, así como su participación en el Concilio Vaticano II y en la reforma litúrgica, le hacen un testigo privilegiado. La presentación de su vida permite conocer de primera mano otros detalles sobre las vicisitudes y anhelos del Movimiento litúrgico en España.

Palabras clave: Garrido Bonaño, movimiento litúrgico, reforma litúrgica, Vaticano II, benedictinos y liturgia.

Han pasado ya seis años del fallecimiento de Manuel Garrido. Tiempo de sentir la ausencia en su Comunidad de la Abadía de la Santa Cruz, y de dar a conocer con perspectiva su vida y su obra. Gracias al trabajo de Ana María Ramírez Vallejo hemos podido acceder al archivo personal conservado en la Abadía ${ }^{1}$. Después de varias consultas, hemos recopilado datos inéditos que completan los perfiles biográficos publicados con ocasión de su fallecimiento ${ }^{2}$. Sirvan estas

1 El Fondo Manuel Garrido Bonaño (MGB) se encuentra en el Archivo de la Abadía de la Santa Cruz del Valle de los Caídos. Consta de 14 cajas que comprenden los años 1947-2012.

2 Santiago Cantera, Garrido Bonaño, Manuel, en Icíar Gómez Hidalgo (coord.), Diccionario Biográfico Español, t. 22, Madrid, 2009, pp. 496-97; Juan Pablo RUBIO, In memoriam: Manuel Garrido Bonaño, OSB (1925-2013), en Phase, 318 (2013), pp. 699-700; Francisco Xavier ARÓZTEGUI, 
páginas como homenaje y como estímulo para futuras investigaciones sobre el Movimiento litúrgico en España ${ }^{3}$.

\section{NACIMIENTO, INFANCIA Y JUVENTUD}

Manuel Garrido nació en Valverde del Camino (Huelva) el 1 de octubre de 1925. Sus padres, Francisco Garrido Ramírez y Sebastiana Bonaño Ramírez, transmitieron a sus hijos (Diego, José y Dominga) un estilo de vida sencillo y austero, de profunda raíz cristiana. Manuel fue bautizado el 26 de octubre en su parroquia de María Santísima del Reposo, iglesia a la que estuvo ligada su vida: allí mismo fue confirmado el 29 de octubre de 1928 por Mons. Eustaquio Ilundain ${ }^{4}$; y el 29 de abril de 1932 recibió la Primera Comunión ${ }^{5}$.

Estudió en el Colegio de María Auxiladora, dirigido por las Hijas de María Auxiliadora. En este ambiente, muy pronto prendió en él la inquietud vocacional, tal como rememoraba años después: «he recordado muchas veces, además de otros motivos sobrenaturales, a los "cursillistas" de Valverde del Camino (...); a los muchachos que el Señor puso a mi paso y me manifestaron sus ansias de superación y sus deseos de altura; a mis hermanos en el sacerdocio, muchos de ellos compañeros desde mi infancia ${ }^{6}$. Empezó entonces los estudios eclesiásticos: cursó Ingreso y Primer Curso en la Preceptoría de Valverde del Camino 7 . En septiembre de 1940 solicitó la entrada en el Seminario de Sevilla; fue aceptado por el

In memoriam: P. Manuel Garrido Bonaño OSB, en Liturgia y espiritualidad, 44 (2013), pp. 549-550. Cfr. además: Bernardo VELADO, El movimiento litúrgico en España hasta el Concilio Vaticano II, en AA.VV., El Movimiento Litúrgico y la Reforma Litúrgica, Barcelona, 2009, pp. 25-85. Para su bibliografía hasta el año 1995, cfr. Anthony WARD y Cuthbert JOHNSON, Orbis Liturgicus: repertorium peritorum nostrae aetatis in re liturgica, Roma, 1995, pp. 162-167.

3 Agradezco a Alejandro Arenas su trabajo en la primera recopilación del material sobre la vida y la obra de Manuel Garrido, antes de que se abriera y ordenara el archivo personal. Algunos párrafos de este artículo han sido publicados en un breve perfil biográfico en Studia Monastica (2020), en imprenta. Allí además aparece toda la bibliografía de nuestro autor.

4 Mons. Eustaquio Ilundain (1862-1937) era entonces Cardenal Arzobispo de Sevilla, provincia eclesiástica a la que también pertenecía Huelva.

5 Cfr. Partida de Bautismo y Confirmación (26.VII.1946), firmada por Francisco Cruces Martín, coadjutor de dicha parroquia, en Archivo Monasterio de Silos (AMS), Partidas de Bautismo, carp. $1 / 64$.

6 Cipriano VAGagGINI, El sentido teológico de la liturgia: ensayo de liturgia teológica general, Madrid, $1965^{2}$, Prólogo de Manuel Garrido, p. XVII.

7 Sobre su traslado al Seminario y sus estudios allí: cfr. Archivo General Arzobispado de Sevilla (AGAS) Fondo Seminario. Secretaría, caja 152, expediente 74. 
Rector D. Francisco J. Marín y se matriculó directamente en el $2^{\circ}$ curso. En esos meses se puso enfermo y tuvo que regresar a su casa; una vez recuperado, presentó un informe médico y volvió a solicitar el ingreso en septiembre de 1941 para el siguiente curso, ya con un nuevo Rector, D. Avelino Esteban. Sus aptitudes para el estudio y su buen comportamiento le acompañan en estos años de Sevilla, donde estudió los dos primeros cursos de Filosofía (cursos 1942-1944).

No obstante, otra inquietud rondaba el corazón de Manuel. Por su correspondencia personal sabemos cuánto le afectó la muerte de su padre (1946) y cómo iba dirigiendo sus pasos hacia la vida monástica ${ }^{9}$. El 24 de octubre de ese año, el Abad de Silos escribe al Arzobispado de Sevilla para informar de que Manuel se había presentado para pedir el Santo Hábito de la $\operatorname{Orden}^{10}$. En noviembre o diciembre de ese año Manuel hizo unos días de retiro espiritual, y se trasladó a Silos, donde enseguida -quizá por ser seminarista- tomó el hábito el mismo día 17 de diciembre ${ }^{11}$.

\section{EN LA ABADÍA DE SILOS}

Este antiguo monasterio castellano está ubicado en el Valle de Tapadillo, perteneciente al municipio burgalés de Santo Domingo de Silos. Estuvo abandonado más de cuarenta años a causa de la exclaustración decretada, en 1835, durante el gobierno de Mendizábal ${ }^{12}$. Un grupo de monjes benedictinos franceses ${ }^{13}$, procedentes de San Pedro Solesmes y de San Martín de Ligugé14, llegaron en 1880 a

8 Cfr. Informe del Cardenal Segura y Sáenz, 11.XII.1946, en Archivo Monasterio de Silos (AMS), Cartas testimoniales, 2/73. Se lee que Manuel era «sereno, atento, formal y humilde». En MGB, caja 1 , carp. 1, fotografía de mayo de 1944 , donde anota $\ll 1^{\circ}$ de Filosofía».

9 Cartas de Manuel Lorenzo y Peñalva (31.X.1946 y 4.XII.1946), MGB, caja 4, carp. 1. El P. Manuel Lorenzo fue canónigo de Sevilla y director espiritual del Seminario. No constan otras fechas. En las testimoniales del Cardenal Segura (vid. supra), se dice: «Ha salido voluntariamente del Seminario por vocación religiosa».

10 AGAS. Fondo Arzobispal. Gobierno. Asuntos Despachados. Año 1946. Órdenes Religiosas Masculinas, $n^{\circ} 2$ Benedictinos.

11 AMS, Libros 2, f. 86v-87.

12 Cfr. Quintiliano Tajadura y Tajadura, Menologio Silense, Burgos, 1979, p. 35; Manuel RE-

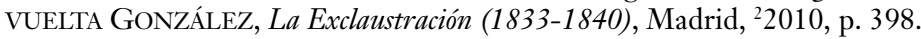

13 Procedentes de San Pedro Solesmes y de San Martín de Legugé: cfr. Quintiliano TaJadura Y TAjadura, Menologio Silense [ver n. 12], p. 33.

14 Tras el decreto del 29 de marzo de 1880, todos los religiosos franceses fueron expulsados: cfr. Félix María CASTRILlejo IbáÑEZ, El monasterio benedictino de Santo Domingo de Silos en el siglo XIX, en José Antonio FERNÁNDEZ FLÓREZ (dir.), Silos, un milenio: actas del Congreso Internacional sobre la Abadía de Santo Domingo de Silos, t. 2, Burgos, 2003, p. 380. 
este monasterio con Alphonse Guépin como superior. En 1894 este monasterio fue canónicamente restablecido como abadía y el P. Guépin fue su primer abad ${ }^{15}$.

Cuando Manuel Garrido ingresó en Silos, el tercer abad después de la restauración era Isaac María Toribios, quien hacía unos meses había sido elegido por la comunidad ${ }^{16}$. El joven Manuel venía del seminario y ya había realizado los estudios de filosofía y latín. Como recuerda el P. José Ignacio González, por norma general los candidatos al noviciado benedictino eran admitidos a edad temprana, porque se les conocía a través de la Escolanía y del Seminario Menor; no era el caso de Manuel, quien fue admitido como novicio a una edad, que ya en ese tiempo se consideraba como «vocación tardía», por la mentalidad de entonces ${ }^{17}$.

El paso del seminario de Sevilla al monasterio de Silos no fue fácil, debido a su salud frágil y a las condiciones precarias que entonces tenía el monasterio.

A los dos años del noviciado, el padre Manuel Garrido Bonaño profesó los votos temporales el 29 de junio de 1948. El mismo día, tres años después, los votos solemnes ${ }^{18}$. Fue ordenado sacerdote en Silos por Mons. Pérez Platero, el 27 de julio de 1952 y, a los pocos días, cantó Misa solemne en la parroquia de su niñez ${ }^{19}$.

En Silos conoció a Santiago Alameda ${ }^{20}$, hombre de gran talla intelectual y que murió con fama de santidad. En 1946, el padre Santiago tenía el cargo de

15 Dom Alphonse Guépin (1836-1917) fue biógrafo y propagador de las enseñanzas de Guéranger. Abad restaurador del monasterio de Silos (1880-1917), cfr. Quintiliano TAJADURA Y TAJADURA, Menologio Silense [ver n. 12], pp. 43-44.

16 Isaac María Toribios, OSB (1897-1961): fue el tercer Abad después de la restauración del monasterio de Santo Domingo de Silos desde el 8.XI.1944 hasta el 5.XI.1961. Entre sus principales obras en favor de la comunidad benedictina se encuentran la restauración de la vida cenobítica en San Salvador de Leyre, la independencia del priorato de Santa María de Estíbaliz (Álava) y la fundación de la Abadía de la Santa Cruz del Valle de los Caídos: cfr. Quintiliano TAJADURA Y TAJADURA, Menologio Silense [ver n. 12], pp. 77-81.

17 El P. José Ignacio González Villanueva (1954) es monje de la Abadía de la Santa Cruz del Valle de los Caídos desde el año 1970. Conoció al Padre Garrido desde los ocho años: cfr. José Ignacio GONZÁLEZ Villanueva, Entrevista al padre fosé Ignacio González Villanueva, Abadía de la Santa Cruz del Valle de los Caídos, 15 de julio de 2015.

18 AMS, carp. profesiones, orden alfabético.

19 Cfr. Santiago CanTera, Garrido Bonaño... [ver n. 2], p. 496; cfr. Francisco Arroyo, Homilía en sus Bodas de Oro (31.V.2002), Iglesia Parroquial Ntra. Señora del Reposo (MGB, caja 1, carp. 4).

20 Santiago Alameda Beltrán, nació en Covarrubias en 1891. Profesó en 1908. Finalizó sus estudios de filosofía escolástica y al comenzar sus estudios de teología, fue enviado al Colegio Internacional Benedictino (Ateneo Pontificio) San Anselmo de Roma, donde llegó a ser condiscípulo de Odo Casel. Después de doctorarse allí, fue ordenado sacerdote en 1914. Desde 1915 a 1928 fue profesor de teología y filosofía en Silos. En 1928 fue enviado al priorato de Estíbaliz (Álava). Regresó a Silos y fue nombrado por el Abad Isaac María Toribios, como prior y maestro de hermanos (1945). En 
prior y maestro de hermanos. En seguida descubrió las cualidades de Manuel y por eso, desde muy joven, le animó a la enseñanza y a su primera publicación en la Revista Liturgia de Silos en 1950. Fue su primer mentor y le ayudó, con mucha suavidad y caridad, a superar tanto sus dificultades vocacionale ${ }^{21}$ como las humanas, pues poseía la prudencia, serenidad de juicio y moderación en el hablar y al corregir ${ }^{22}$. Manuel, por su parte, se consideró discípulo suyo y le reconoció como «maestro de la espiritualidad del oficio divino ${ }^{23}$.

Como profesor de Filosofía, Manuel comenzó a enseñar a los monjes estudiantes de Silos desde el año 1950, aunque sobre esta materia nada ha escrito. El P. Alameda le alentó a profundizar en la sagrada liturgia, que luego se convertiría en el centro de sus múltiples actividades ${ }^{24}$. Asimismo, le animó a incorporarse a la Sociedad Mariológica Española ${ }^{25}$, de la que llegó a ser miembro desde $1953^{26}$. Incluso pidió que le sustituyera en la XIII Asamblea Mariológica con una conferencia sobre san Bernardo y la liturgia ${ }^{27}$. También participó en los Coloquios de Pastoral Litúrgica de Begoña, en agosto de 1954. Era el preludio de una vida hacendosa: los acontecimientos iban a virar dos veces en pocos meses.

\section{FUNDACIÓN EN LEYRE Y ESTUDIOS EN ROMA}

El padre Garrido fue llamado junto con otros a fundar el Monasterio de San Salvador de Leyre (Navarra) ${ }^{28}$. Transcurría el año 1954, y el 10 de noviembre, un

1948 vuelve a enseñar teología y filosofía. En 1952 vuelve a Estíbaliz como prior y regresa en 1954 a Silos hasta 1958 en que por enfermedad tiene el cargo de subprior. Murió el 3 de abril de 1963: cfr. Quintiliano TAJADURA Y TAJADURA, Menologio Silense [ver n. 12], pp. 83-84; Manuel GARRIDO BONAÑO, Grandes maestros y promotores del Movimiento Litúrgico, Madrid, 2008, pp. 149-150.

21 José Ignacio GONZÁleZ VILlanUEVA, Entrevista al padre Fosé Ignacio González... [ver n. 17].

22 Cfr. Quintiliano Tajadura y Tajadura, Menologio Silense [ver n. 12], p. 149.

23 Manuel GaRRIDO, Grandes maestros... [ver n. 20], p. 149.

24 Por ejemplo, el P. Manuel fue un conferenciante de fama en España, durante los años 50: cfr. Manuel GARRIDO, Grandes maestros... [ver n. 20], p. 224.

25 Cfr. Santiago CanTera, Garrido Bonaño... [ver n. 2], p. 497. A juicio de Linage Conde, el padre Garrido combinó «la mariología y los estudios litúrgicos, como lo había hecho dom Santiago Alameda en Silos»: Antonio LINAGE CONDE, San Benito y los benedictinos. La Edad Contemporánea, t. $6 / 2$, Braga, 1993 , p. 3432 .

26 «Miembros de la Sociedad Mariológica Española», www.sociedadmariologica.com/Autores, consultado el 15.09.2015.

27 Carta de S. Alameda (7.X.1952), MGB, caja 14, carp. 2.

28 «staban destinados al nuevo monasterio el P. Prior D. Mariano Bravo y los jóvenes estudiantes de teología con sus profesores, más cuatro hermanos»: cfr. Augusto PASCUAL, Veinticinco años de 
contingente compuesto de dieciocho monjes de la abadía de Silos ${ }^{29}$ se establecía en el viejo cenobio, para reanudar una nueva etapa de vida monástica ${ }^{30}$.

Los inicios fueron costosos y no faltaron pruebas e incomodidades para aquellos operarios de la primera hora ${ }^{31}$. Una de las aspiraciones de las autoridades navarras, al llamar a los benedictinos silenses, era convertir el más famoso cenobio del viejo reino en un centro espiritual y cultural para toda Navarra; y a esa labor se entregó el padre Manuel: alternando sus clases con los monjes estudiantes, colaboraba con la revista Liturgia y con la organización de cursillos en Navarra ${ }^{32}$.

Pero su estancia en Leyre fue corta: al año siguiente de comenzar la fundación, fue designado por el Abad de Silos, Isaac María Toribios, para seguir los cursos del Instituto Monástico en el Pontificio Ateneo de San Anselmo de Roma $^{33}$. Las circunstancias de su elección no fueron nada felices: iba a Roma para reemplazar a un monje de Silos que había abandonado la vida religiosa ${ }^{34}$. Llegó probablemente en octubre de 1954, abatido y acongojado por las circunstancias.

A mediados de los cincuenta, el Ateneo se encontraba en un momento de fuerte vitalidad. Durante sus estudios allí $(1955-1957)^{35}$, pudo conocer y recibir

restauración monástica en Leyre (1954-1979), en AA.VV., Leyre, cuna y corazón del Reino: cincuenta años de la restauración del monasterio (Analecta Legerensia, 2), Yesa, 2005, p. 509. Aunque no consta en los libros de los Consejos de 1954-1955 de Silos, se cita a Manuel Garrido junto a otros cuatro profesores: cfr. Tomás MORAL CONTRERAS, La cultura entre los benedictinos de la restauración legerense (1954-2004), en AA.VV., Leyre, cuna y corazón del Reino: cincuenta años de la restauración del monasterio (Analecta Legerensia, 2), Yesa, 2005, p. 526.

29 Cfr. Constancio Del Alamo MarTíneZ, Silos: Cien años de historia, 1880-1980, Madrid, 1983, pp. 177-178.

$30 \mathrm{Al}$ igual que el Monasterio de Silos, el cisterciense de Leyre sufrió también la ley de la exclaustración de Mendizábal desde el 19 de febrero de 1836: cfr. Tomás MORAL CONTRERAS, Monasterio de San Salvador de Leyre, Madrid, 1988, p. 21.

31 Cfr. Tomás Moral ConTreras, Monasterio de San Salvador... [ver n. 30], p. 34.

32 Tomás Moral Contreras, La cultura entre los benedictinos... [ver n. 28], p. 526.

33 El Colegio San Anselmo de Roma fue fundado en 1687 como centro de estudios teológicos de la Congregación benedictina de Montecasino (cfr. Antonio LinAGE Conde, San Benito y los benedictinos, La Edad Moderna, t. 3/1, Braga, 1993, p. 1149). Años después, dentro del Colegio se erigieron dos institutos: el Institutum Liturgicum Anselmianum fundado en 1950 y renovado radicalmente en 1961 (cfr. Alfonso BERLANGA GAONA, Liturgia y teología. Del dilema a la sintesis, Barcelona, 2013, p. 51) y el Istituto Monastico en 1952.

34 Por la correspondencia con el Abad de Silos, el P. Isaac, conocemos algunos detalles de su estancia. Le enviaba allí - dice en su primera carta- para dar buen ejemplo y ocupar la plaza que había dejado el monje huido: MGB, Carta de Isaac Toribio (Silos, 4.XI.1955), caja 3, carp. 3.

35 Así consta en el Liber Annualis del Pontificio Instituto Litúrgico de San Anselmo (años académicos 1955-56; 1956-1957). En algunos perfiles biográficos hay imprecisiones sobre sus años de estudios en Roma. 
clases de destacados profesores como Hallinger ${ }^{36}$, Steidle ${ }^{37}$, Calati ${ }^{38}$, y Vagaggini entre otros ${ }^{39}$.

Como decíamos, en la Ciudad eterna entró en escena uno de sus grandes referentes en liturgia, después del P. Alameda: Cipriano Vagaggini ${ }^{40}$. Asistió a sus clases y quedó impresionado: encontraba una visión renovada de la liturgia que, superando el peligro del rubricismo o del alegorismo, entroncaba el culto de la Iglesia con la tradición bíblica y patrística, en la unidad de la historia de la salvación. Fruto de ese encuentro, concibió dos proyectos para cuando regresara a España ${ }^{41}$ : dar a conocer a Vagaggini con la traducción de su obra Il senso teologico della liturgia ${ }^{42}$, y

36 Johannes-Josef, P. Kassius Hallinger OSB, de la Abadía de Münsterschwarzach. Es el creador del Corpus Consuetudinum Monasticarum. Doctor en filosofía de la Universidad de Würzburg. Enseñó en el Pontificio Ateneo San Anselmo de Roma las materias de Historia de la Iglesia de la Edad Media y la Edad Moderna, en el periodo 1949-1980: cfr. Kassius HALLIGER, Personalangaben und Schriftenübersicht, en Joachim F. ANGERER y Josef LENZENWEGER, J. (eds.), Consuetudines Monasticae: eine Festgabe für Kassius Hallinger aus Anlass seines 70. Geburtstages (Studia Anselmiana, 85), Roma, 1982, pp. 19-22.

37 Basilio Steidle OSB (1903-1982), de la Archiabadía de Beuron (Hohenzollern). Doctor en teología por el Instituto Pontificio San Anselmo. Enseñó Patrología en el mismo desde 1952 hasta su jubilación: Alexandre OLIVAR, El padre Basilio Steidle. Una evocación, en Studia monástica, 24 (1982) pp. 415-417.

38 Benedetto Calati OSB (1914-2000), de la Congregación Camaldulense. En los años 50 fue invitado por Vagaggini a ocuparse de la cátedra de Espiritualidad Monástica Medieval en el Instituto Monástico, puesto que ocupará más de treinta años: cfr. Guido Innocenzo GARGANO, Padre Benedetto Calati: Sapienza di un monaco a camaldoli, en Alessandra CISLAGHI y Giordano REMONDI, G. (A cura di), Sapienza monastica: saggi di storia, spiritualità e problemi monastici (Studia Anselmiana, 117), Roma, 1994, pp. 15-65.

39 Cfr. Juan Pablo RuBIO, In memoriam... [ver n. 2], pp. 699-700. El archivo asegura que se conserva la ficha de las calificaciones, así como la firma y las fotos de los profesores de las materias que cursó. Lo hemos consultado repetidas veces y por el momento no aparecen.

40 Cipriano Vagaggini OSB (1909-1999), de la Abadía de Saint-André (Bélgica). Realizó estudios de filosofía y teología en el Pontificio Ateneo San Anselmo. En sus primeros años como investigador (1945-1960) se dedicó a profundizar en la naturaleza y método de la teología. Parte de esta investigación se publicó bajo el título de Il senso teologico della liturgia. Destacó en la preparación, desarrollo y aplicación del Concilio Vaticano II [a él se debe la Introducción y el capítulo primero de la constitución Sacrosanctum concilium, así como el primer proyecto de la Encíclica Mysterium fidei de Pablo VI: cfr. Manuel GARRIDO, Grandes maestros... [ver n. 20], p. 260]. En 1969 fue nombrado miembro de la Comisión Teológica Internacional y en 1974, Rector del Pontificio Ateneo San Anselmo. Y el mismo año, consultor de la Congregación para la Educación Católica y Seminarios: cfr. Alfonso BERLANGA GAONA, Liturgia y teología... [ver n. 33], pp. 71-74.

41 Cfr. Juan Pablo RuBIO, In memoriam... [ver n. 2], p. 700.

42 Vagaggini tenía en mente un proyecto de publicar una serie de volúmenes de introducción a la teología. Había recopilado material -unas veinte cajas- entre 1945-1960, año en que fue llamado para colaborar en la preparación del Concilio (cfr. Achille Maria TRIACCA, Dom Cipriano Vagaggini, oSB cam [1909-1999]. In memoriam, en Ephemerides Liturgicae, 113 [1999], p. 453). En 1957, Vagaggini publicó parte de este material. Esa primera edición fue la que conoció y tradujo el P. Garrido. 
escribir un nuevo manual -su Curso de Liturgia Romana (1961)- que aportase una presentación teológica, espiritual, participativa y transformante de la misma. A estas dos tareas dedicó buena parte de su trabajo en los siguientes años.

Transcurren los meses romanos entre el estudio, las clases y la elaboración de su tesis para obtener el Diploma de Estudios Monásticos. El tema elegido fue el de los fenómenos místicos en una obra de Rufini, bajo este título en latín: $D e$ phaenomenis mysticis in Historia Monachorum Rufini ${ }^{43}$.

En abril de 1957 su Abad le anima a acabar bien los últimos exámenes ${ }^{44}$. Así, el 28 de junio recibió el deseado Diploma y abandonó por el momento Roma, camino de Silos.

\section{REGRESO DE ROMA}

El P. Manuel se incorporó a la vida de la comunidad en Silos, previo paso por Leyre a recoger sus pertenencias. En la Bibliografía general de Garrido pueden verse sus numerosas publicaciones en la revista Liturgia (Silos) en estos años. Tan sólo tenemos una noticia de una actividad externa: su participación en la Semana de Estudios sobre el Ritual, que tuvo lugar en el Monasterio de Montserrat en el mes de septiembre. De nuevo su salud, quizá con la llegada del invierno, le impide continuar en Silos y va a recuperarse de la ciática a Valverde del Camino junto a su madre. No sabemos cuándo regresa a Silos, pero en enero de 1958 sigue en Valverde ${ }^{45}$.

Este año de 1957 tiene su importancia para los benedictinos en España. Como es sabido, al acabar la guerra civil española, el jefe del estado, el general Francisco Franco Bahamonde decidió construir una basílica con la finalidad de albergar, en el cementerio anejo a ella, a los fallecidos de la Guerra Civil ${ }^{46}$. Inicialmente se pretendió que la atendiese una comunidad religiosa de vida activa; sin embargo, se prefirió una orden monástica. La Abadía de Santo Domingo de Silos recibió el encargo de administrarla ${ }^{47}$. El entonces Abad, Isaac $M^{a}$ Toribios

43 MGB, Curriculum vitae (10.III.1967), caja 12, carp. 15.

44 Carta del Abad de Silos (IV.1957, sin día), MGB, caja 3, carp. 3.

45 Cfr. Carta del P. Isaac Toribios (1.I.1958), MGB, caja 3, carp. 3.

46 Recientemente se ha publicado un estudio sobre la historia de este lugar emblemático: cfr. Fernando OlMEDA, El Valle de los Caídos: una memoria de España, Barcelona, 2019.

47 Cfr. Daniel Sueiro, La verdadera historia del Valle de los Caídos, Madrid, ${ }^{1} 1976$, p. 208. En el capítulo diecinueve de este libro (que lleva por título «Confesiones de Fray Justo Pérez de Urbel») están transcritas, a partir una grabación en cinta magnetofónica, unas conversaciones sostenidas con Fray Justo, en el Colegio Mayor Márquez de la Ensenada (Madrid), en el verano de 1976. 
Ramos, aceptó la solicitud del Jefe del Estado, y preparó con Justo Pérez de Urbel $^{48}$ la nueva fundación ${ }^{49}$. El 23 de agosto de 1957 se publicó el decreto-ley, y el 27 de mayo de 1958, mediante el Breve Pontificio Stat Crux ${ }^{50}$, se erigió la Abadía, dentro del capítulo general de la Congregación de Solesmes. El 17 de julio de 1958 comenzó una nueva comunidad benedictina: la Abadía de la Santa Cruz del Valle de los Caídos. Ese día iniciaron vida en comunidad veinte monjes con Justo Pérez de Urbel como su primer abad ${ }^{51}$.

El P. Garrido vivió con intensidad la puesta en marcha de esta nueva fundación ${ }^{52}$. El Abad de Silos había consultado previamente a sus monjes; el P. Garrido mostró su disponibilidad, pero no fue elegido y debía permanecer en Silos y asumir las muchas tareas vacantes que dejaban los monjes que se marchaban. Mientras se ultimaban los preparativos para la fundación, el Garrido decidió dirigirse al Abad de Solesmes, el P. Cozien, para referirle la situación personal que atravesaba entonces. El Abad de Solesmes, en carta del 4 de septiembre de 1958, respondía preocupado por la situación. Entramos así en un breve paréntesis de su vida sobre el que hay pocos indicios o documentos. Por su malestar-según se desprende de su relato ${ }^{53}$ - parece verosímil que, desde el verano de 1958, Garrido

48 Justo Pérez de Urbel Santiago (1895-1979) inició su vida monástica en Santo Domingo de Silos. Autor prolífico de trabajos históricos y literarios (Hagiografía, Historia, Liturgia y Arte). Alternó sus investigaciones con la traducción de obras inglesas y alemanas. Doctor en filosofía e historia por la Universidad de Madrid, donde enseñó Historia de la Edad Media: cfr. ibid., 99-101.

49 En realidad, fue el mismo Franco quien se lo propuso al portavoz de la Comunidad silense, Justo Pérez de Urbel y fue éste quien se lo transmite al abad de Silos en los primeros días de 1957: cfr. Constantino Del Álamo Martínez, Silos: Cien años... [ver n. 29], p. 178; Cfr. Daniel Sueiro, La verdadera bistoria del Valle... [ver n. 47], p. 208.

50 PíO XII, Stat Crux, en Acta Apostolicae Sedis, 51 (1959), pp. 643-644.

51 Cfr. Constantino Del Álamo Martínez, Silos: Cien años... [ver n. 29], p. 179; Cfr. Daniel SueIRO, La verdadera historia del Valle... [ver n. 47], p. 210.

52 Conocemos su versión de los hechos por un Dossier que preparó, a modo de cuenta de conciencia muy detallado, escrito a máquina, 5 hojas tamaño A-5, mecanografiadas: Cfr. Dossier sobre su estancia en el Monasterio de Santa Cruz del Valle de los Caídos (28.VI.1975), MGB, caja 1, carp. 2.

53 Cfr. Dossier sobre su estancia en el Monasterio de Santa Cruz, p. 1. No existen muchos documentos para corroborar la estancia en un lugar y en otro con precisión. El recuerdo de los monjes de Leyre es borroso y nadie recuerda una segunda etapa (ni siquiera breve) allí; pero Garrido lo sostiene en su Dossier. También se conserva una postal que apoyaría la versión de Garrido (Postal para Manuel Garrido a Silos (9.IX.1959): allí está tachado «Silos» y aparece escrito «A Leyre». Hay más correspondencia enviada a Leyre en octubre de ese año: MGB, caja 12, carp. 9), pero no es concluyente, pues no sabemos si la recibió en Valverde después. Más bien estamos ante una situación anómala donde se junta el rigor de la vida en Leyre para la que no estaba preparado y la situación de falta de entendimiento en Silos. Es de justicia reconocer que Silos atravesaba un periodo difícil, pues debía sostener varias fundaciones simultáneamente: Estíbaliz, San Benito de Buenos Aires, San Rafael en México, Montserrat en Madrid, Leyre y el Valle de los Caídos. 
alternase periodos en Silos, en Leyre y en su pueblo natal. De este modo procuró sobrellevar este periodo que le había afectado también a su salud. Durante su recuperación recibió de nuevo el apoyo del Abad de Solesmes, el P. J. Prou, a fin de que pudiera solicitar su traslado al P. Abad del Valle, Justo Pérez de Urbel. Éste le mostró su acogida repetidas veces ${ }^{54}$; el traslado parecía entonces estar solucionado, pero el Abad de Silos cambió repentinamente de parecer. En esos días coincidieron el Abad y el P. Garrido en Madrid unos días y, después de varias conversaciones, accedió el P. Isaac a dar su permiso para el traslado al Valle. En abril o mayo de 1960 el P. Garrido llegó finalmente a la Abadía de la Santa Cruz ${ }^{55}$.

Pasaron unos meses de pacífica convivencia en el Valle. Recibió el encargo de hospedero y de bibliotecario ${ }^{56}$. En varios periodos se ocupó de la biblioteca, durante los cuales procuró adquirir, estudiar y situar las fuentes litúrgicas, patrísticas e históricas ${ }^{57}$. Gracias a este interés, la biblioteca del Valle de los Caídos, en tan corto tiempo de existencia, posee una amplia colección de libros.

Vista la situación, el P. Garrido creyó que había llegado el momento de firmar la estabilidad en ese Monasterio; pero de nuevo los pareceres discrepaban: ni el Abad de Silos ni el Abad de Solesmes en su Visita Canónica al Valle (1961) le daban el visto bueno. Esta situación se prolongó con diversos vaivenes que no son del caso para un perfil biográfico de este tipo. Más adelante veremos cómo se desarrollaron los acontecimientos.

Estas vicisitudes no impidieron que este periodo (julio de 1957-mayo de 1960) fuese fructífero. Como señalábamos antes, Garrido continúa como colaborador habitual de varias revistas de liturgia y teología: Liturgia (Silos), Estudios Marianos y Vida sobrenatural. Fueron además unos meses donde pudo dedicarse a aquellos dos proyectos que había trazado en Roma. La traducción de la obra de Vagaggini fue su prioridad nada más llegar a España ${ }^{58}$, aunque lo alternaba con la escritura de su Curso de Liturgia Romana. El 21 de marzo de 1959, fiesta de san Benito abad ${ }^{59}$, se

54 Cfr. Dossier sobre su estancia en el Monasterio de Santa Cruz (28.VI.1975), donde se citan las palabras textuales de Fray Justo en carta del 21.I y 14.III de 1960.

55 Carta del P. Alonso, 16.IV.1960, dirigida al P. Garrido al Valle: MGB, caja 2, carp. 2.

56 Cfr. Liber actuum Capituli Sanctae Crucis de Valle Occasorum (5.XI.1960), 17. En la promulgación de los cargos de la comunidad, el P. Garrido es nombrado $4^{\circ}$ ayudante de la Hospedería y $1^{\circ} \mathrm{Bi}$ bliotecario.

57 Ocupó el cargo de bibliotecario en varios periodos: 1960-1962; 1964-1969; 1990-1992; 1993 1995: cfr. Liber actuum Capituli Sanctae Crucis de Valle Occasorum.

58 Carta de Cipriano Vagaggini (11.IX.1957), donde le agradece además la traducción de Il senso teologico que le está haciendo: MGB, caja 4, carp. 3.

59 El 21 de marzo el Calendario monástico celebra el Tránsito de San Benito. 
acabó de imprimir la traducción de la voluminosa obra de Vagaggini en la editorial BAC de Madrid. Los elogios de Garrido en el Prólogo de la edición española evidencian la admiración por el autor. Estaba impresionado de la síntesis litúrgica y teológica de Vagaggini que no había encontrado en otros autores leídos por él, tales como Guéranger, Righetti, Jungmann, Azcárate, Alameda, Prado ni en revistas de liturgia como La Maison-Dieu o Les questions liturgiques ${ }^{60}$. Pasados los años, sus alumnos percibieron estos nuevos enfoques; para Garrido -recuerda alguno de ellos- la liturgia era verdadera teología, una realidad anamnética. La liturgia-que ya era el centro de su vida- se volvió más profunda, menos teórica; liturgia y teología estaban unidas en su vida. Este bagaje intelectual se manifestó también en el modo de organizar y de vivir las celebraciones litúrgicas ${ }^{61}$.

A continuación, Garrido centró sus esfuerzos en su manual de liturgia. Comenzó a redactarlo en San Salvador de Leyre en $1959^{62}$ y fue publicado a comienzos del año $1961^{63}$. El Curso de Liturgia Romana tuvo una única edición ${ }^{64}$ y fue muy estudiado en España ${ }^{65}$. Y como espaldarazo por esta publicación le llegó una carta de felicitación del mismo Vagaggini ${ }^{66}$. La obra -prologada por Justo Pérez de Urbel- está dirigida principalmente a los aspirantes al sacerdocio, a los sacerdotes y a todos los fieles que quisieran vivir hondamente la liturgia oficial de la Iglesia y, a la vez, profundizar en el conocimiento de los ritos y del sentido de los signos y fiestas. Por su esquema, aparato crítico y tono de exposición, puede ser considerado como un manual de liturgia ${ }^{67}$. No se trata de una obra puramente

60 Cfr. Cipriano VAGagGINI, El sentido teológico... [ver n. 6], p. xvi.

61 Juan Pablo RuBio, Entrevista al padre Rubio, Abadía de la Santa Cruz del Valle de los Caídos, 15 de julio de 2015.

62 Cfr. Tomás Moral Contreras, Monasterio de San Salvador de Leyre... [ver n. 30], p. 34; cfr. Tomás MORAL CONTRERAS, La cultura entre los benedictinos... [ver n. 28], p. 526.

63 El 10 de febrero de 1961: Manuel GARRIDO, Curso de Liturgia Romana, Madrid, 1961, p. 751.

64 No nos consta que la obra tuviera reimpresiones. La primera tirada fue de 220 unidades: 100 de tela y 120 de plástico.

65 Mariano Palacios nos da cuenta de la amplia difusión que tuvo el manual a los dos años de publicarse. Resalta varias características: el hecho de que estuviera en sintonía con el Movimiento litúrgico vigente; la bibliografía actualizada; la amplitud de temas y la carencia de otro manual en castellano que fuera tan completo. Además - tras la publicación de la Constitución sobre Sacra Liturgia donde la liturgia se considera como asignatura principal en los programas de estudio (n. 16 y Optatam totius n. 16)- lo propone como libro de consulta en los Seminarios: cfr. Miguel PALACIOS, Por un programa de liturgia para los Seminarios, Liturgia, 12 (1964), p. 104; Joan BELLAVISTA, Bibliografía. Reseña de Curso de liturgia romana, en Boletín de Pastoral litúrgica, 4 (1961) p. 31.

66 Carta de C. Vagaggini (16.VIII.1961), MGB, caja 4, carp. 3.

67 Durante el tiempo que se gestó el movimiento litúrgico español se redactaron varios libros sobre liturgia. Algunos incorporaron el título de «manual» y otros no. Entre los primeros figuran dos publicaciones: en 1921 Gregorio Martínez de Antoñana: Manual de Liturgia, y en 1935 el padre 
rubricista $^{68}$, sino que sabe coordinar el aspecto histórico, arqueológico, literario, y sobre todo, teológico y pastoral ${ }^{69}$.

Pronto la fama del P. Garrido se fue extendiendo. Eran los meses previos a la apertura del Concilio Vaticano II y, con grata sorpresa, se le anuncia el nombramiento como asesor de los obispos españoles ${ }^{70}$, a través de la carta de Mons. Casimiro Morcillo, Arzobispo de Zaragoza, con fecha 14 de septiembre, donde le pide su respuesta ${ }^{71}$. La decisión y la propuesta de su nombramiento tuvieron lugar en Segovia el 8 de julio de 1962 durante un retiro preparatorio de los obispos $^{72}$, tres meses antes de la inauguración. Mientras tanto, en ese mismo verano, tenemos constancia de la participación del P. Manuel en la VI Semana de Estudios Josefinos, en Ávila ${ }^{73}$.

El 20 de septiembre la tranquilidad estival se vio alterada por una nueva carta de Mons. Casimiro Morcillo, donde se le comunica el efectivo nombramiento $^{74}$. Se suceden jornadas intensas de trabajo en Madrid para preparar un elenco

Germán Prado: Curso popular de liturgia. Entre los segundos, el cardenal Isidro Gomá publica en 1918 el libro El valor educativo de la liturgia católica, y en 1930 el padre Alfonso María Gubianas, Nociones elementales de liturgia. En el Movimiento litúrgico en Portugal sobresale una obra del mismo título: Curso de Liturgia Romana de dom Antonio Coelho (1926).

68 En el sentido de una exposición de casuísticas minuciosas donde se discuten todas las normas ceremoniales a que debe someterse el culto: cfr. Manuel GARRIDO, Curso de Liturgia Romana... [ver n. 63], p. xv.

69 La obra consta de cinco partes y un total de quince capítulos. Posee doble autoría: la parte correspondiente a la Liturgia eucarística está enteramente redactada por Dom Antonio Pascual Díez OSB; el resto, por Manuel Garrido. Como apéndice figuran los documentos Mediator Dei y Musicae Sacrae disciplina; la Instrucción de la Sagrada congregación de Ritos sobre la música y liturgia sagradas; y el texto latino del Código de rúbricas sagradas con notas explicativas.

70 Una precisión respecto al término «asesor» $\mathrm{O}$ «perito». El reglamento del Concilio distinguía dos tipos: los conciliares estrictamente tales, directamente elegidos por el papa; y los peritos privados, cuyas atribuciones son esencialmente de apoyo y consulta de los obispos o grupos de ellos autorizados a usar la documentación conciliar que les transmitan ellos y por tanto obligados al secreto. El padre Garrido fue elegido perito privado.

71 Cfr. MGB, caja 7, carp. 4. Allí don Casimiro le da la lista completa de los consultores del episcopado español. Garrido acepta el nombramiento en carta del 24 de septiembre.

72 Fueron designados además los siguientes liturgistas: Gregorio María de Antoñana, CMF; Adalberto Franquesa, OSB; Francisco Sánchez, OSB; e Ignacio Oñatibia.

73 Cfr. Fotografía en el Convento de San José (Ávila, 31.VIII.1962): MGB, caja 1. Y correspondencia con miembros de la Asociación Josefológica, Carta (2.II.1962), caja 14, carp. 6.

74 La fuente documental para los pormenores de su estancia romana y los prolegómenos es un cuaderno escrito a mano que Garrido titula Diario del Concilio. Son más de 160 caras en tamaño A5, escritas a mano, donde cuenta con detalle todo lo ocurrido. Empieza el 20 de septiembre y termina el 6 de diciembre de 1962. Las últimas páginas, al acabársele las hojas del cuaderno, son cuartillas sueltas que anexa. Lo conserva actualmente el P. Juan Pablo Rubio, quien lo recibió como donación personal del mismo P. Manuel. 
bibliográfico para la consulta de los obispos y que había que enviar a Roma. Los días 26 a 30 de septiembre los dedicó a la discusión y valoración de los esquemas previos sobre el documento de liturgia. El día 11 televisaron la inauguración del Concilio en Roma que él siguió con emoción. Días más tarde, el 16 de octubre, recibió un telegrama para que se traslade urgentemente a Roma ${ }^{75}$; de nuevo fueron días de agitación para resolver los trámites del pasaporte en la Dirección General de Seguridad y obtener el billete de avión. Pudo volar con Iberia desde Madrid el 19 octubre y aterrizar en el Aeropuerto de Fiumicino a las 2 de la tarde. Se alojó en el Colegio Español y ya ese mismo día prestó juramento de secreto ante el Secretario del Episcopado Español, Mons. Tarancón. El ritmo de trabajo subió de intensidad y aún tuvo tiempo de asistir a dos reuniones: la primera con todos los consultores de liturgia, Escritura y teología; la segunda, la reunión plenaria con todos los obispos españoles ${ }^{76}$.

\section{ESTANCIA EN ROMA DURANTE EL VATICANO II, REGRESO AL VALLE Y NUEVOS ENCARGOS EN ROMA}

No queremos hacer prolija la narración de esta etapa, pero nos gustaría destacar al menos algunos aspectos de su trabajo en Roma, donde se percibe su mente teológica y litúrgica. El ambiente de efervescencia de esas jornadas romanas no le impidió trabajar con intensidad en la biblioteca del Anselmiano, o mantener conversaciones con algunos antiguos profesores y, en especial, con Vagaggini. Pudo asistir activamente a las reuniones -improvisadas o no- con sus colegas consultores de liturgia o con grupos de obispos que solicitaban su parecer. También aprovechó los días de asueto, cuando no había reuniones en el aula conciliar, para «romanizarse», como él mismo decía.

En la lectura de su Diario hay un propósito claro: servir a la Iglesia asesorando a los obispos españoles -que no siempre tenían la adecuada preparación en esta materia ${ }^{77}$ - y la defensa del esquema sobre la liturgia y de su carácter teológico. En este sentido, se esmeró en preparar las consultas que le solicitaron acerca de la Misa, del carácter sacramental de la liturgia y de los principios para

75 Cfr. Telegrama (16.X.1962), MGB, caja 1, carp. 2. Era el día en que la Congregación general del Concilio comunicó que el concilio comenzaría por el examen del esquema de liturgia (cfr. Manuel GARRIDO BonaÑo, La reforma litúrgica después del Vaticano II, Madrid, 1988, p. 26).

76 Diario del Concilio, día 19 de octubre, 23-24.

77 Cfr. Diario del Concilio, día 27 de octubre, 51. 
llevar a cabo otras reformas ${ }^{78}$. Como sucede en otros grupos de trabajo, Garrido mantenía diferencias de criterio con los otros dos consultores -Oñatibia y Franquesa-, o con quienes seguían acríticamente las afirmaciones sobre liturgia del ya famoso Salvatore Marsili ${ }^{79}$. Subyacía aquí la conocida diatriba ${ }^{80}$ entre la posición de Vagaggini -artífice de gran parte del esquema sobre la liturgia presentado en el aula conciliar- y Marsili, cuya conferencia por escrito -afirma Garrido, sin dar más datos- fue distribuida a los padres conciliares. De esto último Garrido se lamenta $^{81}$. Su adhesión a Vagaggini es total de palabra y por escrito; de hecho -así lo recuerda él mismo- en ese periodo los dos libros de consulta que no faltaban en su escritorio eran precisamente: El sentido teológico de la liturgia y su Curso de Liturgia Romana ${ }^{82}$.

En suma, el padre Garrido participó en las dos primeras sesiones del Concilio del 19 de octubre al 8 de diciembre de 1962, y del 29 de septiembre al 6 de diciembre de $1963^{83}$, precisamente en las jornadas en que el papa Pablo VI promulgaba la Constitución Sacrosanctum concilium. La primera etapa dejó huella en Manuel Garrido, tal como rememoraba: fueron días de enorme trabajo para discutir y presentar el esquema sobre la liturgia, con un total de 625 votos de los Padres, 15 congregaciones generales y 329 intervenciones de los Padres ${ }^{84}$. El día 4 de diciembre de 1962 fue a la compañía Iberia para arreglar su billete; partió de Roma el día 6 rumbo a Madrid. Su llegada al Valle fue sólo una parada en el camino para los nuevos retos que estaban a punto de llegar.

78 Cfr. Diario del Concilio, día 26 de octubre, 47.

79 Salvatore Marsili (1910-1983), OSB cam, hizo su profesión monástica en 1931 en la Abadía de Finalpia. Conoció a Odo Casel y a Ildefonso Herwegen en sus estancias en la Abadía de Maria Laach (1932; 1934-1935). Fue Preside del Pontificio Istituto Liturgico desde 1961-1972. Su propuesta sobre el carácter mistérico de la liturgia ha tenido eco en numerosos autores en toda Europa. Fue profesor además en otros centros pontificios en Roma, como el Laterano y la Universidad Gregoriana.

80 Cfr. Julián LÓPEz MARTíN, En el Espiritu y en la Verdad. Introducción teológica a la Liturgia, t. 1, Salamanca, ${ }^{2} 1993$, pp. 368ss.

81 Cfr. Diario del Concilio, día 7 de noviembre, 88.

82 Cfr. Diario del Concilio, día 28 de octubre, 54.

83 Lamentablemente, de la segunda etapa en Roma no hay diario ni anotaciones. Debemos contentarnos con sus páginas de su libro La reforma litúrgica... [ver n. 75], pp. 27ss.

84 La discusión del primer esquema de la liturgia ocupó a los padres conciliares desde el 22 de octubre al 13 de noviembre de 1962. El día 14 de noviembre fue votado y aprobado, pero aún con observaciones y enmiendas que fueron después estudiadas e introducidas en el siguiente texto. Éste fue sometido a votación de nuevo el 22 de noviembre de 1963 (con 20 votos en contra). De nuevo el 4 de diciembre se votó el texto definitivo, en presencia de Pablo VI: cfr. Diario del Concilio, día 17 de noviembre, 128. 
Aunque no faltaron invitaciones ${ }^{85}$, los siguientes meses fueron un tiempo para reposar las experiencias vividas. La temática de sus artículos en este periodo (1963-1965) se centra en la Mariología litúrgica y en lo viejo y lo nuevo en la liturgia, a propósito de SC y de la reforma; tema este último que no abandonará nunca y del que llega a escribir, en colaboración con otros consultores como Oñatibia y Franquesa, el famoso Comentario a la constitución sobre la sagrada liturgia (BAC, 1965) y, posteriormente, su monografía La reforma litúrgica $(1988)^{86}$.

No mucho después recibió tres notificaciones algo desconcertantes por el viraje de los acontecimientos: la primera, en carta de agosto de 1964, el anuncio de que no asistiría a la III ${ }^{\mathrm{a}}$ sesión del Concilio ${ }^{87}$; la segunda, su nombramiento como consultor de la Sagrada Congregación de Ritos ${ }^{88}$; en tercer lugar, la carta del cardenal Tarancón, presidente de la Comisión Episcopal de Liturgia en España, donde se le anuncia su nombramiento como perito de dicha Comisión ${ }^{89}$. Su nombramiento como consultor en la Congregación de Ritos le dio la posibilidad de participar en el Coetus interpretationum del Consilium para aplicar la reforma litúrgica; con este fin estuvo en Roma del 29.IX al 4.XII de 1965. A diferencia de su primera estancia, esta vez no disponemos de fuentes documentales: no hay diario, ni anotaciones de ningún tipo ${ }^{90}$.

85 Tenemos constancia de que fue a la Semana de Liturgia para el Instituto de Teología Pastoral de la Confer (4-9 febrero), al Curso de Liturgia en Mondoñedo-Ferrol (12-14 julio) y a la Semana del Apostolado Litúrgico (El Escorial, 19-23 de agosto): MGB, caja 9, carp. 5.

86 En esta última obra Garrido expone su pensamiento con claridad meridiana. A su juicio, el doble organismo para la puesta en práctica de la reforma litúrgica (la Congregación de Ritos y el Consilium) dio lugar a roces, humillaciones y confusiones (p. 38). Hubo esfuerzos, sin embargo, en que jurídicamente se alcanzara una concordancia de ambos organismos y un procedimiento para la publicación de documentos sobre liturgia. Con la posterior reforma de la Curia se atenuó esto y el Consilium quedó como un organismo técnico no jurídico. Finalmente, el cardenal Lercaro (Presidente del Consilium) y el cardenal Larraona (Prefecto de Ritos) renunciaron, y se nombró a una única cabeza, el cardenal Gut, OSB.

87 Celebrada en Roma del 14 de septiembre al 21 de noviembre de 1964. Cfr. Carta (18.VIII.1964), MGB, caja 7, carp. 4, celebrada en Roma del 14 de septiembre al 21 de noviembre de 1964. Sin embargo, le piden que revise el esquema sobre la libertad religiosa (Carta de J. Ma Eguaras, desde Málaga, 13.VII.1965).

88 Cfr. Manuel GaRrido Bonaño, La reforma litúrgica... [ver n. 75], p. 38.

89 Cfr. Carta de Vicente E. Tarancón, arzobispo de Oviedo (13.I.1965), MGB, caja 2, carp. 2. La Comisión de Liturgia se había creado ese mismo mes.

90 Los documentos que se conservan son: un billete-permiso de alojamiento en el Palazzo della Cancelleria (9-13.XI.1965), y las relaciones en latín de lo tratado en ellas: MGB, caja 7, carp. 4. Asimismo, hay una carta enviada por el Abad de Silos para Garrido al Colegio San Anselmo (8.XI.1965): MGB, caja 3, carp. 3. El 8 de abril de 1968, el Cardenal Gut confirmó a Garrido como consultor de la Congregación de Ritos por un quinquenio. Pero no se materializó, porque el 8 de mayo de 1969, con la reforma de la Curia, apareció la Congregación del Culto Divino: cfr. Manuel GARRIDO BONAÑO, La reforma litúrgica... [ver n. 75], pp. 40-41. 


\section{EN Y DESDE LA ABADÍA DE LA SANTA CRUZ}

Como era de suponer, toda esta labor por más que fuese escondida, acabó por darle un nombre al P. Garrido en España. Ya era miembro de la Sociedad Josefológica desde 1962, y de la Asociación Mariológica Española desde 1953. Diez años después fue nombrado miembro adjunto de la Pontificia Academia Mariana Internacional. También la Facultad de Teología del Norte de España (sede Burgos) contrató al P. Garrido para su claustro, ya desde el curso 19671968. Años más tarde lo encontramos colaborando en dos causas de beatificación: la del sacerdote español fundador del Opus Dei, Josemaría Escrivá de Balaguer (1902-1975), y la causa Sor Eusebia Palomino (1899-1935). Habría que añadir además sus encargos en la comunidad y la propia investigación. La suma total de todos estos frentes junto a su condición de perito de la Comisión de Liturgia, nos permite imaginar el ingente trabajo del P. Garrido y el número de invitaciones recibidas en estos años. Para sintetizar esta etapa de su vida, presentamos dos apartados:

\section{A. En el Valle, de puertas para adentro}

Con el paso del tiempo la comunidad de la Abadía de la Santa Cruz asumió nuevos retos. La puesta en marcha de la Escolanía en 1958 supuso la llegada de un buen grupo de muchachos que necesitaban formación musical, escolar y espiritual. El P. Garrido fue director y confesor de la Escolanía varios años, encargo que compatibilizó con los que ya tenía (bibliotecario, confesor de novicios, hospedero, prefecto de estudios, profesor...). Así lo recuerda Santiago Cantera: «en estos oficios, gracias a su labor, la biblioteca del monasterio se incrementó considerablemente, procuró fomentar la vida espiritual de los niños escolanos animándoles a participar en iniciativas de conocimiento de la liturgia y de ayuda a las misiones, y logró que los monjes pudieran realizar los estudios de Filosofía y Teología en el propio cenobio salvaguardando mejor la clausura» ${ }^{91}$.

Respecto a su situación canónica nos habíamos quedado en 1960 con su llegada al Valle. Para ello, retomamos de nuevo su Dossier: después de unos meses allí, pensó que era el momento de pedir la estabilidad en el Valle y así lo solicitó

91 Santiago Cantera, Necrológica. P. Manuel Garrido Bonaño, OSB, en web oficial de la Abadía de la Santa Cruz <http://www.valledeloscaidos.es/noticias/2013/fallecimiento-del-p-manuel-garridoosb>. 
por carta al Abad de Silos, quien le responde con una negativa. Cuando fray Justo Pérez de Urbel dimitió como abad en el Valle (1968), Garrido lo intentó de nuevo, pidiendo entonces el traslado a Silos o a alguna de sus fundaciones ${ }^{92}$. Esta vez su solicitud es atendida ${ }^{93}$; sin embargo, un incendio en Silos imposibilitó el traslado. La situación no tenía visos de cambiar, por lo que reiteró su petición el 6 de abril de $1975^{94}$. Las circunstancias y las necesidades de la Abadía de la Santa Cruz exigían que permaneciese allí, según decidieron de común acuerdo el Abad de Silos y el del Valle (Luis María Lojendio ${ }^{95}$ ). No lo veía así el P. Garrido quien, desahogándose en el Dossier que hemos consultado ${ }^{96}$, manifiesta su sufrimiento por encontrarse en tierra de nadie, en una situación inestable durante quince años. No hay más noticias sobre esto hasta que el Libro de las Actas Capitulares de la Abadía de la Santa Cruz recoge esta anotación: «Incardinación P. Manuel Garrido» con fecha 15 de agosto de $1987^{97}$. En esa hoja se recoge la concesión de estabilidad en dicha Abadía por parte del entonces abad, fray Emilio-María Aparicio Olmos, previa autorización del Abad de Silos (Pedro Alonso), con el voto de dos tercios de la comunidad y la notificación al Abad de Solesmes.

Termina felizmente un camino sinuoso que permite el P. Garrido intervenir de pleno derecho en los asuntos de la comunidad, así como asumir más responsabilidades. En los Cuadernos de información local, boletín que recoge la vida y la actividad en torno al Valle de los Caídos, se da fe de su actividad efervescente en distintos puntos de la geografía española. El material disponible en el fondo MGB está incompleto, por lo que presentamos con menos orden algunos retazos de esta etapa.

\section{B. Viajes e intervenciones, docencia en Burgos y su servicio como consultor del Secretariado de liturgia}

Como decíamos antes, su prestigio trajo consigo un número elevado de invitaciones a distintos foros de formación teológica, simposios y semanas de estudio. Se conservan en el fondo MGB esquemas de conferencias, programas de

\footnotetext{
92 Cfr. Dossier, con ref. a una Carta suya fechada el 1.X.1968.

93 Cfr. Dossier, con ref. a una Carta del P. Abad de Silos fechada el 3.VII.1970.

94 Aunque él reconoce en su Dossier que estaba pensando en ir a una de las fundaciones y no a Silos: concretamente al «pequeño Montserrat» (Madrid).

95 Abad desde el 18.XII.1968 hasta 1979.

96 Firmado el 28 de junio de 1975.

97 Este acto jurídico se encuentra en el folio 107 del Liber actuum Capituli Sanctae Crucis de Valle Occasorum.
} 
cursos y correspondencia sin ningún orden, en torno a la espiritualidad litúrgica, al nuevo breviario, al sacerdocio y al papel de la Virgen María. Es un material variopinto con datos exactos de la celebración de esos encuentros; y en otras ocasiones apenas se dan referencias del año o del lugar. Presentamos a continuación un bosquejo que permita al lector hacerse cargo de su tarea desde finales de los 60 hasta la década de los 80 .

En los cursos académicos 1966-1969 colaboró con el Instituto de Espiritualidad de los Carmelitas Descalzos, con sede en Burgos. Su docencia casi coincide con el nombramiento para el claustro de la Facultad de Teología del Norte de España, antes mencionada ${ }^{98}$. Aceptar este cargo no estuvo exento de dificultades iniciales, pues tuvo que ponerse de acuerdo con el Abad (Pedro Alonso) y con el Prior (Ismael Fernández de la Cuesta) para el reparto de las clases ${ }^{99}$. Como se dijo antes, comenzó las clases en el curso 1967-68. En los calendarios académicos pueden verse los títulos de sus cursos: Cuestiones especiales de liturgia (1967-1971), Sacramentología litúrgica: oraciones eucarísticas (1972-1973), El formulario litúrgico: el monacato (1973-74), El lenguaje en los nuevos textos litúrgicos (1974-75), Historia de la oración cristiana (1976-77), Ministerios y culto (1979-1980) y Eucaristía y liturgia: documentos y doctrina (1981-1984). Como corresponde a tal cargo, en esos años dirigió algunas tesis de licenciatura y de doctorado ${ }^{100}$; también leyó la Lección inaugural del curso 1980-1981 101 y participó en diversos encuentros académicos de esos años ${ }^{102}$. El último curso fue el año 1983-84, cuando Garrido rechazó un curso de liturgia por problemas de espalda y otras razones personales, que no menciona. En este centro teológico coincidió con José Antonio Abad, liturgista, con el que luego llevó a cabo algunos proyectos y con quien mantuvo siempre una buena amistad ${ }^{103}$.

98 Otros profesores extraordinarios que también entraron a colaborar con esta Facultad fueron: José Antonio Abad, Melquíades Andrés, José María Caballero... Cfr. MGB cajas 12 y 13.

99 Cfr. Carta del Abad de Silos (16.X.1967), MGB, caja 12, carp. 18. Hay además en esa misma carpeta varias cartas que mencionan la tirantez para la asignación de una cátedra, que no le fue concedida. Es una cuestión colateral sobre la que no queremos tratar en este escrito.

${ }^{100}$ Hay constancia de una para cada grado: de licenciatura con Pedro Caraza sobre Amalario de Metz (febrero de 1982) y una de doctorado con Ernesto Zaragoza Pascual sobre teología espiritual (cfr. MGB, caja 13, carp. 3).

101 Cfr. MGB, caja 12, carp. 18.

102 Como el XIV Simposio Internacional de Teología del sacerdocio (9-11.VII.1981), donde pronunció una conferencia sobre la vertiente sacerdotal del supremo pontificado en las fuentes litúrgicas: cfr. MGB, caja 12, carp. 18.

${ }^{103}$ En 1986, Ediciones Palabra propuso a José Antonio Abad la elaboración de un tratado de liturgia que pudiera servir para la comprensión de la liturgia renovada a instancias del Vaticano II. Así lo 
En la década de los 70-80 aceptó otras invitaciones dentro y fuera de España. La Pontificia Academia Mariana Internacional le pidió una intervención en Zagreb en el verano de $1971^{104}$; la Asociación de Josefología, un año antes, para su Simposio Internazionale en Roma (29.XI-6.XII), y también para otro encuentro en Montreal (Canadá). En los tres casos su Abad no vio conveniente el viaje y no le dio permiso para asistir, por lo que otros leyeron su intervención ${ }^{105}$. En cambio, pudo participar en enero de 1981, junto con otra veintena de teólogos españoles, en el Simposio teológico organizado por el International Institute of the Heart of fesus en Santiago de Chile; la misma institución contó con él para otro Congreso de teología pastoral en Toulouse durante el verano de ese mismo año ${ }^{106}$.

Por su parte, entre sus intervenciones en territorio nacional ${ }^{107}$ podemos reseñar las conferencias sobre la Liturgia de las Horas a los Hermanos de la Instrucción cristiana (18-23.VIII.1975), los Cursillos de Liturgia y Música para religiosas en 1972, sus cuatro conferencias en el Monasterio de Yuste (1982), o las intervenciones en varios Simposios anuales de Teología de la Universidad de Navarra ${ }^{108}$ (1982-1984 y 1989); y, por último, el Congreso Internacional sobre San Bernardo (Orense, 1991).

Pasemos a su trabajo como consultor en el Secretariado Nacional de Liturgia. Con la toma de posesión de su cargo, el 30 de enero de 1965, bajo el mandato de

recuerda él mismo: «Entré en contacto por escrito con el Padre Garrido y le faltó tiempo para asumir con entusiasmo el proyecto. Nos dividimos el material, más o menos por la mitad, y yo me encargué de darle unidad literaria a todo el volumen. El padre Garrido sabía mucha liturgia y escribía muy bien a máquina. En cambio, no corregía en exceso los originales. Por este motivo, se retrasó un poco la publicación, a pesar de que él envió pronto los originales que le correspondían. Finalmente, el volumen estuvo en la calle en 1988. Luego se han hecho sucesivas ediciones. Durante el tiempo que impartió clases en licenciatura en la Facultad residía en la Residencia de Profesores que tiene la misma Facultad (calle Martínez del Campo, 10) y nos veíamos con frecuencia y siempre con gran cordialidad por su parte (...). Los alumnos apreciaban su sabiduría (...)» (Entrevista a fosé Antonio Abad, Burgos, 12 de abril de 2018).

${ }_{104}$ Cfr. MGB, caja 14, carp. 4. Fue publicada en 1971 bajo el título: La Virgen María en los himnos litúrgicos de sus fiestas.

105 Cfr. MGB, caja 14, carp. 6. Como ya se dijo, colaboró en otros encuentros de esta Pontifica Academia, tal como consta en su Bibliografía (años 1983 y 1987), pero desconocemos si asistió finalmente.

106 Cfr. MGB, Correspondencia con Roger Vekemans y Jesús Solano, sj, caja 9, carp. 9.

107 Cfr. MGB, caja 8, carps. 5-6; caja 9, carp. 5. También en su Archivo se recoge abundante material de sus cursos para otras instituciones con las que colaboró (Ateneo de Teología, el Centro Mariano Cor Mariae Centrum...): cfr. MGB, caja 12, carps. 16 y 17.

108 Con temática diversa: el señorío de Cristo en Adviento y Navidad, sobre la sacramentalidad de la liturgia y su incidencia en la teología y en la pastoral, el sacramento de la Penitencia a la luz del Vaticano II, y la Iglesia como pueblo de Dios en el Misal de Pablo VI. 
José María Martín Patino, sj (1966-1971), el P. Garrido asume distintos encargos. Se conservan algunas cartas oficiales donde recibe consultas de temas variados ${ }^{109}$ : el diaconado permanente, el altar, el calendario, la comunión en la mano, la elaboración del Leccionario... e incluso sobre la reforma de la Semana Santa, esta vez desde el Consilium, a través del P. Martín Patino ${ }^{110}$. En algunas intervino directamente y en otras el P. Garrido conserva la documentación de estudio ${ }^{111}$.

La actividad del Secretariado era intensa. Se hacía necesaria la traducción de los textos de la liturgia, así como la adaptación de los ritos de los sacramentos ${ }^{112}$. Manuel Garrido figura como vocal para el Calendario, junto a Pere Farnés y Manuel Ramos. Las reuniones plenarias, así como las de los grupos de trabajo, ocupaban el tiempo de estos consultores. Asimismo, el Secretariado organizó varias Jornadas Nacionales para los Responsables diocesanos de liturgia: era un modo de divulgar la reforma litúrgica y de conocer de primera mano el impacto de la misma en cada diócesis ${ }^{113}$.

No tenemos más detalles sobre su trabajo como consultor ni conocemos otras circunstancias, exceptuada una carta dirigida al Cardenal Tarancón en mayo de 1969. Allí expone las dificultades que ha detectado en la traducción de algunos textos bíblicos y litúrgicos, y en la musicalización del Salterio para la Liturgia de las Horas. Y, junto a otras circunstancias de la reforma litúrgica, manifiesta su desazón por la falta de comunicación entre el Secretariado y algunos de los consultores, entre los que se incluye; se trata de un verdadero desahogo donde el P. Garrido anima con exquisito respeto al Cardenal para que tome medidas, al tiempo que pone el cargo de consultor a su disposición. Esta carta -así anota con fecha 25.III.1970- no tuvo respuesta ${ }^{114}$.

109 Cfr. MGB, caja 3, carps. 1-2.

110 Cfr. Carta del 22.VI.1967, MGB, caja 2, carp. 2.

111 Basta cotejar el índice del fondo MGB para conocer la temática de dichas consultas (caja 2, carps. 2-5 y caja 3, carps. 1-2): informes (sobre el Calendario Nacional de santos, la oración de los fieles, la introducción de la lengua vernácula en el canon...), estudios (las antífonas de comunión, el leccionario litúrgico ferial y el dominical, la comunión en la mano...).

112 Se conserva la lista completa de los consultores para cada una de las Comisiones encargadas de la adaptación, encabezadas por el responsable: Bautismo (I. Oñatibia), Matrimonio (I. García), Exequias (J. Llopis), Reforma de la Semana Santa (P. Farnés), Calendario (J. A. Gracia), Epacta nacional (F. Resines y M. Luengo Tapia) y Traducciones (sin definir responsable, pero encabezados por P. Farnés y L. Maldonado).

113 En su bibliografía aparecen estudios sobre los libros litúrgicos de la reforma: El misterio de la unión bipostática en el misal de Paulo VI, en Scripta Theologica, 11 (1979), pp. 105-126; o bien escribió directamente sobre los avatares de la reforma: Reforma litúrgica posconciliar y renovación espiritual de la Iglesia, en La Vida Sobrenatural, 60 (1980) pp. 124-128; pp. 203-210; pp. 267-276.

114 Cfr. Carta al Excmo. y Revdo. Sr. D. Vicente Enrique Tarancón (21.V.1969): MGB, caja 2, carp. 3. 
Un último aspecto reseñable es su colaboración -igualmente oculta- en dos procesos de beatificación: el de Josemaría Escrivá de Balaguer y el de Sor Eusebia Palomino ${ }^{115}$. En el primer caso intervino en el Tribunal Diocesano de Madrid ${ }^{116}$; en el segundo, fue su promotor. Guardaba un grato recuerdo para esta salesa fallecida en Valverde del Camino. A partir del material de este segundo proceso, publicó trabajos de diversa índole sobre su vida, escritos y epistolario ${ }^{117}$.

\section{VII. ÚLTIMOS DÍAS}

Resulta difícil presentar las obras de su último periodo. Como recuerda uno de sus semblantes biográficos, publicó «tanto en revistas especializadas como en otras de divulgación y de alta difusión y en periódicos diversos, además de colaborar en programas religiosos de radio» ${ }^{118}$. Además, quien se acerque a su $\mathrm{Bi}$ bliografía ${ }^{119}$ descubrirá obras variadas que van desde las monografías y manuales (La Liturgia de las Horas a través de los siglos, Iniciación a la liturgia de la Iglesia, La reforma litúrgica después del Vaticano II... hasta su último libro Grandes promotores del Movimiento litúrgico), hasta biografías (Ildefonso, cardenal Schuster, mistico y apóstol), y varias ediciones y traducciones de otros autores (san Ambrosio, san León Magno, Itala Mela...).

Como mariólogo, publicó numerosos artículos en las principales revistas de esta materia: Estudios Marianos (con más de cincuenta colaboraciones), Ephemerides Mariologicae, Scripta de Maria o Marianum. Como sabemos, inició la escritura académica en la revista Liturgia (Silos) y acabó convirtiéndose en colaborador de otras revistas de temática teológica, pastoral y espiritual. Publicó habitualmente en Vida sobrenatural acerca de temas de liturgia fundamental (liturgia y oración, comunidad, silencio, su dimensión sagrada) y sobre el Novus Ordo de la Misa (plegarias eucarísticas, los nuevos prefacios...). Otro campo de investigación fue la vida monástica; estudió sus fundamentos bíblicos, la vida y la Regla de san Be-

115 Cfr. Francisco Xavier ARÓzTeguI, In memoriam... [ver n. 2], p. 550.

116 Cfr. Opus Dei, MGB, caja 8, carps. 2-4. Se conservan cartas con los sucesores de san Josemaría y otros fieles del Opus Dei, recortes de prensa, las notas de un curso de retiro predicado por Escrivá de Balaguer y una declaración sobre la erección del Opus Dei como prelatura personal para la Sagrada Congregación de Obispos.

117 Cfr. Proceso de Beatificación de sor Eusebia: MGB, caja 5, carp. 3; caja 6, carps. 1-3; caja 7, carps. 1-3.

118 Santiago CANTERA, Garrido Bonaño... [ver n. 2], p. 497.

119 En unos meses aparecerá su Bibliografía completa en el volumen de 2020 de la revista Studia Monastica. 
nito, la historia del monacato y la vida ejemplar de algunos benedictinos (Pérez de Urbel, Santiago Alameda, el cardenal Dusmet, Antonio de Alvarado...).

$\mathrm{Y}$ junto a estas ocupaciones, «tantas otras cosas por las que ofrecía constantemente sus días y sus pruebas: las intenciones que había llevado siempre en el corazón: la Iglesia, el Papa, la unidad de los cristianos, las misiones, la comunidad, las vocaciones... ${ }^{120}$. Durante los días de su enfermedad, no pudo celebrar los Santos Misterios. Recuerda el padre Joaquín la delicadeza que tenía el padre Garrido para solicitarle su atención sacerdotal ${ }^{121}$.

Estuvo internado en el Hospital de El Escorial donde agonizó en la víspera de la fiesta de la Exaltación de la Santa Cruz, y falleció en la madrugada del 15 de setiembre del 2013 -fiesta de Nuestra Señora de los Dolores, patrona de Valverde del Camino, su lugar de nacimiento- a la edad de ochenta y siete años ${ }^{122}$.

El día anterior, el padre Manuel había podido venerar las reliquias del Lignum Crucis que desde 1960 se conserva en la Abadía, obsequio del papa san Juan XXIII ${ }^{123}$. Como dice el padre Anselmo Álvarez: «esta coincidencia de fechas y acontecimientos litúrgicos puede considerarse algo más que casual cuando confluyen en alguien, que centró su vida en la celebración, en el amor y en el estudio de la liturgia de la Iglesia y, al mismo tiempo, pasó la mayor parte de sus años a la sombra de esta Cruz del Valle y de Nuestra Señora de la Piedad ${ }^{124}$.

Al día siguiente se celebró el funeral y en seguida fue trasladado el féretro en procesión hacia el cementerio de la comunidad de la Abadía acompañado de sus familiares, las autoridades del Patrimonio Nacional y del Ayuntamiento de San Lorenzo de El Escorial, y representantes de comunidades benedictinas y de otras Órdenes.

Con esta investigación sale a la luz una figura del Movimiento litúrgico español. Como hemos comprobado, sintonizó rápidamente con los pioneros y promotores de este Movimiento. Es destacable por su trabajo en la puesta en marcha de la renovación litúrgica antes y después del Vaticano II. Sus monografías atestiguan un conocimiento profundo de la liturgia en sus fuentes y en sus implicaciones prácticas. La labor de divulgación que llevó a cabo extendió el espíritu y la letra del Concilio en materia litúrgica.

120 Anselmo Álvarez, Funeral del P. Manuel Garrido OSB (www.valledeloscaidos.es/homilias/2013/ funeral-del-p-manuel-garrido-osb), consultado el 16.09.2015.

${ }^{121}$ Joaquín Montull, Entrevista al padre Montull, Abadía de la Santa Cruz del Valle de los Caídos, 14 de julio de 2015.

122 Cfr. Anselmo ÁlvareZ, Funeral del P. Manuel Garrido OSB [ver n. 120].

123 Francisco Xavier ARózTEgUI, In memoriam... [ver n. 2], p. 550.

124 Anselmo ÁLVAREZ, Funeral del P. Manuel Garrido OSB [ver n. 120]. 


\section{UN SERVIDOR DE LA RENOVACIÓN LITÚRGICA EN ESPAÑA}

\section{FUENTES Y BIBLIOGRAFÍA}

\section{Fuentes}

Archivo General Arzobispado de Sevilla (AGAS), Fondo Seminario.

Archivo Monasterio de Silos (AMS).

Fondo Manuel Garrido Bonaño (MGB) en el Archivo de la Abadía de la Santa Cruz del Valle de los Caídos, años 1947-2012.

Liber actuum Capituli Sanctae Crucis de Valle Occasorum, Abadía de la Santa Cruz del Valle de los Caídos.

Liber Annualis del Pontificio Instituto Litúrgico de San Anselmo, Roma.

Garrido Bonaño, Manuel, Dossier sobre su estancia en el Monasterio de Santa Cruz del Valle de los Caídos (28.VI.1975), en propiedad de Juan Pablo Rubio, OSB, Abadía de la Santa Cruz del Valle de los Caídos.

- Curso de Liturgia Romana, Madrid, 1961.

- Reforma litúrgica posconciliar y renovación espiritual de la Iglesia, en La Vida Sobrenatural, 60 (1980) pp. 124-128; pp. 203-210; pp. 267-276

- La reforma litúrgica después del Vaticano II, Madrid, 1988.

— Grandes maestros y promotores del Movimiento Litúrgico, Madrid, 2008.

\section{Entrevistas transcritas}

ABAD, José Antonio, Entrevista a Fosé Antonio Abad, Burgos, 12 de abril de 2018

GonZález Villanueva, José Ignacio, Entrevista al padre González Villanueva, Abadía de la Santa Cruz del Valle de los Caídos, 15 de julio de 2015.

Montull, Joaquín, Entrevista al padre Montull, Abadía de la Santa Cruz del Valle de los Caídos, 14 de julio de 2015.

Rubio, Juan Pablo, Entrevista al padre Rubio, Abadía de la Santa Cruz del Valle de los Caídos, 15 de julio de 2015

Fuentes en formato digital

ÁLVAREZ, Anselmo, Funeral del P. Manuel Garrido OSB (www.valledeloscaidos.es/homilias/2013/ funeral-del-p-manuel-garrido-osb).

CANTERA, Santiago, Necrológica. P. Manuel Garrido Bonaño, OSB, en web oficial de la Abadía de la Santa Cruz <http://www.valledeloscaidos.es/noticias/2013/fallecimiento-del-p-manuelgarrido-osb>.

SOCIEDAD MARIOLÓGICA ESPAÑOLA, «Miembros de la Sociedad Mariológica Española», www.sociedadmariologica.com/Autores. 
ANGERER, Joachim F. y LENZENWEGER, Josef J. (eds.), Consuetudines Monasticae: eine Festgabe für Kassius Hallinger aus Anlass seines 70. Geburtstages (Studia Anselmiana, 85), Roma, 1982, pp. 19-22.

AróZTegUI, Francisco Xavier, In memoriam: P. Manuel Garrido Bonaño OSB, en Liturgia y espiritualidad, 44 (2013) pp. 549-550.

Bellavista, Joan, Bibliografía. Reseña de Curso de liturgia romana, en Boletín de Pastoral litúrgica, 4 (1961) p. 31.

Berlanga GaOna, Alfonso, Liturgia y teología. Del dilema a la síntesis, Barcelona, 2013.

CanTera, Santiago, Garrido Bonaño, Manuel, en Icíar GómeZ HiDALGo (coord.), Diccionario Biográfico Español, t. 22, Madrid, 2009, pp. 496-97.

Castrillejo IbáÑEZ, Félix María, El monasterio benedictino de Santo Domingo de Silos en el siglo XIX, en José Antonio FERNÁNDEZ FlÓREZ (dir.), Silos, un milenio: actas del Congreso Internacional sobre la Abadía de Santo Domingo de Silos, t. 2, Burgos, 2003, pp. 353-390.

Del Álamo MaRTíneZ, Constancio, Silos: Cien años de historia, 1880-1980, Madrid, 1983.

Gargano, Guido Innocenzo, Padre Benedetto Calati: Sapienza di un monaco a camaldoli, en Alessandra Cislaghi y Giordano REMONDI, G. (A cura di), Sapienza monastica: saggi di storia, spiritualità e problemi monastici (Studia Anselmiana, 117), Roma, 1994, pp. 15-65.

LiNAGE Conde, Antonio, San Benito y los benedictinos, La Edad Moderna, t. 3/1, Braga, 1993.

- San Benito y los benedictinos. La Edad Contemporánea, t. 6/2, Braga, 1993.

LÓPEZ MARTÍN, Julián, En el Espíritu y en la Verdad. Introducción teológica a la Liturgia, t. 1, Salamanca, ${ }^{2} 1993$.

MORAL CONTRERAS, Tomás, La cultura entre los benedictinos de la restauración legerense (19542004), en AA.VV., Leyre, cuna y corazón del Reino: cincuenta años de la restauración del monasterio (Analecta Legerensia, 2), Yesa, 2005, pp. 525-529.

OlIVAR, Alexandre, El padre Basilio Steidle. Una evocación, en Studia monástica, 24 (1982) pp. 415-417.

OlMEDA, Fernando, El Valle de los Caídos: una memoria de España, Barcelona, 2019.

Palacios, Miguel, Por un programa de liturgia para los Seminarios, Liturgia, 12 (1964), p. 104.

PaSCUAL, Augusto, Veinticinco años de restauración monástica en Leyre (1954-1979), en AA.VV., Leyre, cuna y corazón del Reino: cincuenta años de la restauración del monasterio (Analecta Legerensia, 2), Yesa, 2005, pp. 499-522.

PíO XII, Stat Crux, en Acta Apostolicae Sedis, 51 (1959), pp. 643-644.

Revuelta GonZÁleZ, Manuel, La Exclaustración (1833-1840), Madrid, 22010.

Rubio, Juan Pablo, In memoriam: Manuel Garrido Bonaño, OSB (1925-2013), en Phase, 318 (2013), pp. 699-700.

SueIro, Daniel, La verdadera historia del Valle de los Caídos, Madrid, ${ }^{1} 1976$.

Tajadura Y Tajadura, Quintiliano, Menologio Silense, Burgos, 1979.

TRIACCA, Achille Maria, Dom Cipriano Vagaggini, OSB cam [1909-1999]. In memoriam, en Ephemerides Liturgicae, 113 [1999], pp. 449-465.

VAGAGGINI, Cipriano, El sentido teológico de la liturgia: ensayo de liturgia teológica general, Madrid, $1965^{2}$.

VELADO, Bernardo, El movimiento litúrgico en España hasta el Concilio Vaticano II, en AA.VV., El Movimiento Litúrgico y la Reforma Litúrgica, Barcelona, 2009, pp. 25-85. 


\section{CONVERSACIONES}

0000 
